\title{
Vincenzo Quercioli (1876-1939), researcher and pioneer of the atlas fracture
}

\author{
Maurizio Domenicucci, MD, Demo Eugenio Dugoni, MD, Cristina Mancarella, MD, \\ Alessandro D'Elia, MD, and Paolo Missori, MD \\ Department of Neurology and Psychiatry, Division of Neurosurgery, "Sapienza" University of Rome, Italy
}

\begin{abstract}
A review of early 20th century literature regarding fractures of the atlas led the authors to discover a paper written in Italian by Professor Vincenzo Quercioli in 1908, at that time an assistant surgeon at the University of Siena. The work was published in the journal II Policlinico, which at that time was directed by Professor Francesco Durante. The paper described the first case of a quadripartite fracture of the atlas, and it accurately reported the mechanism of injury, symptoms, neurological examination, treatment, complications, and cause of death of the patient.
\end{abstract}

Quercioli performed an autopsy on the patient and gave a detailed description of anatomopathological features. In particular, he identified the 4 symmetrical fracture lines related to the arches of the atlas and the substantial integrity of the atlantoaxial ligaments, particularly the transverse ligament. Based on those findings, Quercioli concluded that the mechanism of trauma was an axial force. This force passed through the center of the vertebral ring and caused symmetrical displacement and compression of the articular masses.

These concepts of dynamic physics led Quercioli to conclude that, because the atlas is wedge shaped, the masses of the atlas reacted to stress by moving away from the center. This reaction resulted in stretching the front and rear arches, which then fractured at their 4 points of weakness. The integrity of the spinal cord was intact, based on a negative neurological examination for CNS lesions. Thus, he concluded that these injuries were not fatal and could be cured by appropriate treatment with a Minerva cast and, in the presence of swallowing disorders, with a nasogastric tube.

The case described by Quercioli was later mentioned in two classic works on atlas fractures by Sir Geoffrey Jefferson, published in 1920 and 1927. In those works, Jefferson proposed his classification of 5 different anatomopathological classes; this work is widely cited in the literature and should be considered a classic. The patterns and deductions that Jefferson reported on these fractures appeared to draw upon the scientific experience of Quercioli and his description of the quadripartite atlas fracture, which appeared to be unique, even in Jefferson's review. Therefore, the authors believe that they have identified another scientist and pioneer of the atlas fracture in Professor Vincenzo Quercioli. With his brilliant insights, which remain useful and valid, Quercioli led the way to further research on the subject.

http://thejns.org/doi/abs/10.3171/2014.11.SPINE14483

KEY WORDS atlas fracture; cervical spine; classification; Sir Geoffrey Jefferson; Vincenzo Quercioli; history

$\mathrm{C}$ URRENTLY, there is no well-defined, widely recognized classification for fractures of the atlas. In the literature, most works that report on fractures of C-1 cite the classic work of Sir Geoffrey Jefferson (18861961) of 1920, titled "Fracture of the atlas vertebra: report of four cases, and a review of those previously recorded." Based on this work, and the successive paper published in 1927 by the same author, ${ }^{7}$ most authors attribute the classification of 5 types of atlas fractures to Jefferson. ${ }^{5,12}$ Some authors also refer to a "Jefferson fracture," but descriptions vary among double, ${ }^{4}$ tripartite, and quadripartite fractures ${ }^{4,8}$ that involve one or both of the arches of the vertebra, and in some cases, involve the articular masses. ${ }^{2,8,11}$ We reviewed original works from the beginning of the 20th century that described fractures of the atlas, which also included those mentioned by Jefferson in his two classic publications. In doing so, we found a paper by Professor Vincenzo Quercioli (1876-1939), who reported on a particular fracture of the atlas, published in 1908 in the journal Il Policlinico, which at that time was directed by Professor Francesco Durante (1844-1934). ${ }^{10}$ We observed that Quercioli's work represented the first description of a

SUBMITTED May 13, 2014. ACCEPTED November 4, 2014.

INCLUDE WHEN CITING Published online January 2, 2015; DOI: 10.3171/2014.11.SPINE14483.

DISCLOSURE The authors report no conflict of interest concerning the materials or methods used in this study or the findings specified in this paper. 
4-part fracture of the atlas; the fracture was described admirably, in terms of both clinical and pathological symptoms. Moreover, Quercioli provided a complete biomechanical interpretation.

The importance of the findings and arguments presented in Quercioli's work includes the fact that they must be considered in the context of the limited knowledge in the area of atlas fractures at the time it was written. Even today, the findings are of great topical interest; consequently, this work deserves special mention, and we should recognize its value and appreciate the insight of its author, Professor Vincenzo Quercioli. In addition, it is important to note that the original observations of Professor Quercioli in 1908 led the way in drafting the 1920 work by Sir Geoffrey Jefferson. ${ }^{6}$ Historically, however, we have only recognized Jefferson for the first anatomical classification of traumatic fractures of the atlas.

\section{Quercioli's Case Description}

In 1908, in the surgery section of the journal Il Policlinico, which was managed at the time by its founder Professor Francesco Durante, an article was published in Italian titled "Considerazioni cliniche su di un caso di frattura isolata comminuta simmetrica dello atlante senza lesioni midollari in seguito a caduta sul capo" ("Clinical consideration of a case of a comminuted, isolated, symmetric atlas fracture, without spinal cord lesion, subsequent to a head injury;" Fig. 1). ${ }^{10}$ The author was Professor Vincenzo Quercioli, a young doctor of the Institute of General Clinical Surgery, University of Siena, which was directed at that time by Professor Domenico Biondi (1855-1914). Quercioli opened the scientific paper with the statement: "The fracture of the spine that we present is not common; thus, our searches have not found any similar cases in the literature."

That singular case concerned a 60 -year-old man, who had hit the top of his head after falling from an olive tree. Subsequent to the trauma, he was no longer able to support his head, he had difficulty swallowing, he developed a cough, and his voice was impaired to the point of being barely intelligible. The patient was admitted 8 days after the trauma for pneumonia "ab ingestis" due to his difficulty swallowing and the cough. He was treated with the placement of a nasogastric tube. They also performed traction by placing a gauze bandage under the chin and occiput, and attaching a strap with a counter-weight to apply traction; thus, the head was raised when the patient was in a semi-sitting position. They could not apply a Minerva cast, due to the patient's serious respiratory condition.

On clinical examination, the patient's consciousness was preserved, and no motor or sensory disturbances were observed in the limbs. Before traction was applied, the head was hanging on the trunk, incapable of responding to voluntary commands or resisting passive movements; any passive movement provoked intense pain, and head rotation caused loud noises. The patient's tongue was nearly paralyzed, the gag reflex was preserved, he expectorated with fatigue, and he could not form words.

In the days following admission, the patient's pulmonary condition continued to deteriorate, and the fever con-

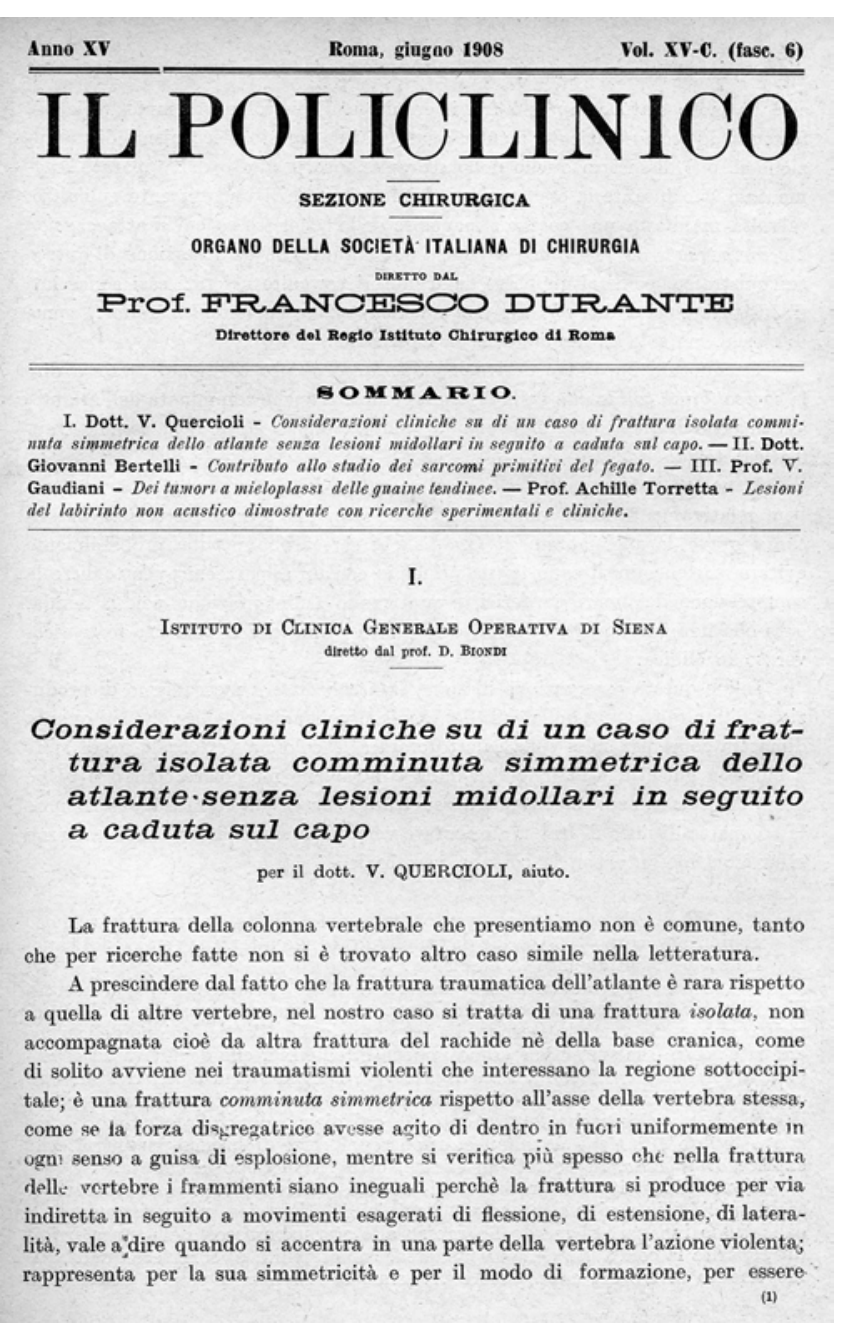

FIG. 1. Original photograph of the front page of Quercioli's original paper titled "Clinical consideration of a case of a comminuted, isolated, symmetric atlas fracture, without spinal cord lesion, subsequent to a head injury," published in II Policlinico in 1908, when the journal was directed by Professor Francesco Durante.

tinued. At 5 days after admission, 13 days after the fall, he died. The day after the death, a necropsy was performed. Quercioli related that, with the cadaver prone, the cervical spine was examined. When the paraspinal muscles were parted, he found that the nuchal ligament was interrupted by a rupture between $\mathrm{C}-1$ and $\mathrm{C}-2$, and the discontinuity could be felt on palpation of the posterior arch of the atlas. The posterior arch of the fractured $\mathrm{C}-1$ vertebra was removed and, when the spinal canal was opened, he found apparently normal meninges, spinal cord, and medulla oblongata, which he then removed.

At this point, Quercioli observed that the odontoid was intact, and the integrity of occipito-odontoid and transverse ligaments was preserved. The anterior arch of $\mathrm{C}-1$ was disconnected from the lateral masses, and they were all removed. The hypoglossal nerve was then removed bilaterally from the base of the tongue up to the origin in the skull; the nerve appeared ecchymotic, with a peppered neurolemma. Microscopic examination (Weigert's solution) showed that the spinal cord was normal, but the 
hypoglossal nerves displayed interfascicular hemorrhage and disrupted myelin. After careful preparation of the bone, the author noted that the atlas was divided into 4 fragments, arranged bisymmetrically (Fig. 2). When the 4 pieces were held together, they matched perfectly; thus, when cemented together with paraffin on the fracture surfaces, the vertebra was completely reconstructed. At this point in the text, the complete fracture lines were accurately described; moreover, the reassembly of the atlantoaxial articulation was described in terms of the pertinent anatomical and articular relationships.

Based on the peculiarities described in the case examined, the author was able to interpret the mechanism that produced the fractured vertebra. First, he considered the parts that would present major, intermediate, and minor resistances. In particular, the areas of greatest resistance would be represented by the joint masses, including the transverse processes. The areas of intermediate resistance would be the midcentral areas of the arches, front and rear. The areas of minor resistance would be the 4 fine lines between the lateral masses and the arches. The disintegrating force must have acted in a manner that uniformly distributed compression and broke all 4 points of least resistance, which caused the vertebra to fracture into 4 symmetrical parts. Also, the force must have traveled from the center of the ring to the outer perimeter with eccentric movement, based on the orientations of the fracture rims: "Tenendo presente che l'atlante contrae rapporti scheletrici diretti con l'occipite e l'epistrofeo solo attraverso le superfici articolari, si deduce che la forza disgregatrice viene trasmessa solo attraverso queste." 10 In other words, considering the inclination of the articular surfaces, which are oriented to form angles with bisectors that intersect in the central part of the atlas, Quercioli stated that the disintegrating force acted in a manner corresponding to the physics of a wedge, which resulted in horizontal and vertical forces. Quercioli also stated that taking into account these considerations of the physics and morphology involved, it becomes clear how the disruptive action is deflected eccentrically, in a lateral direction, and then transmitted to the inclined articular surfaces; you must simply recall that all the conditions are governed by the mode of action of the wedge.

Quercioli then added a quantitative analysis to the qualitative examination of the distribution of forces. He stated that traumatizing violence, represented by the weight of the falling body hitting the top of the head, should be expressed according to a force that runs through the central part of the atlas, and then, through the axis and foramen magnum. This condition would occur when the force acts vertically throughout the body, and the defensive contraction of the neck muscles would cause neck stiffening, which increases the load of the force acting upon the articular wedge of the atlas. At this point, Quercioli focused on the absence of traumatic lesions in the spinal cord, based on the absence of neurological disorders in all 4 limbs observed in the clinical examination of the patient. This observation was verified in the autopsy, which showed normal anatomical and microscopic appearances. The author considered this situation to be related to the small diastasis of the 4 fragments of the atlas, and particularly, the substantial integrity of the transverse and occipi-

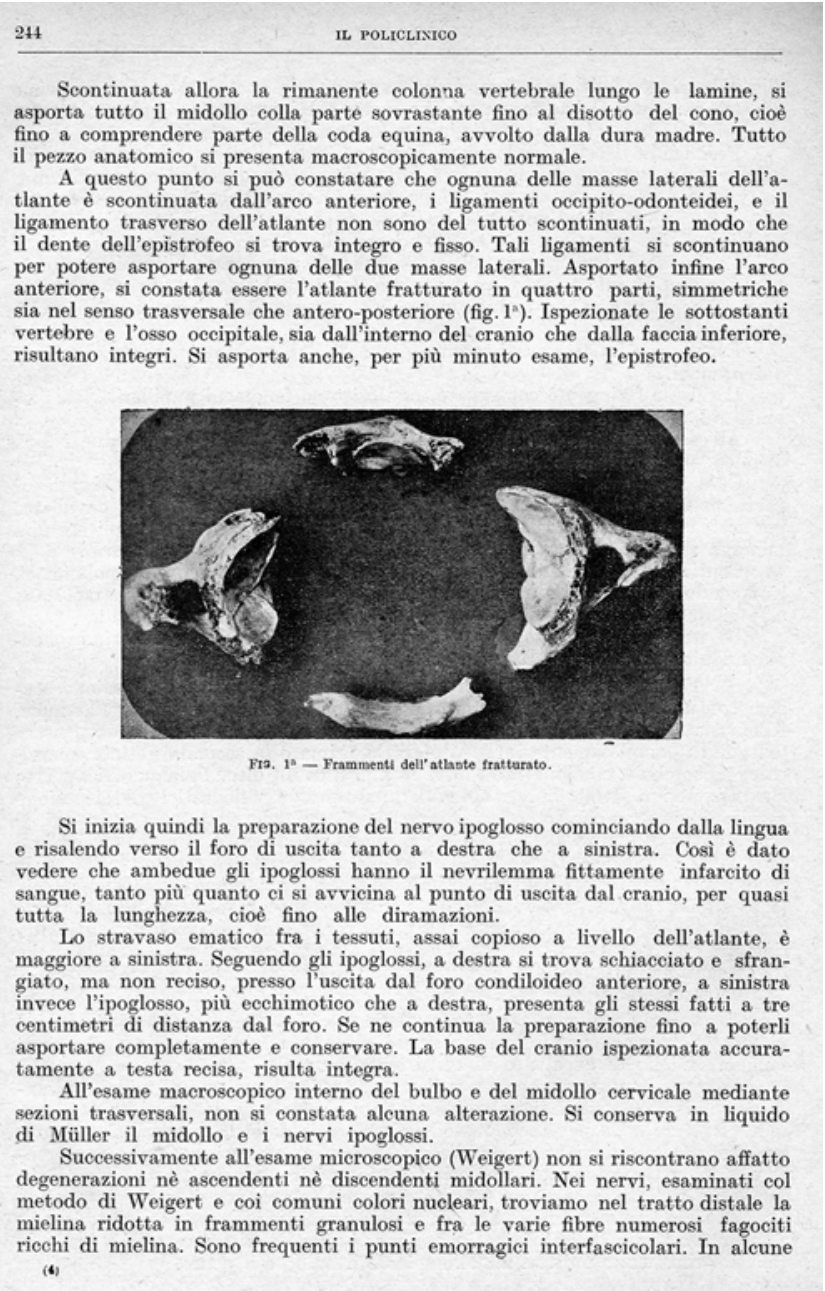

FIG. 2. Original photograph of page 244 of the paper written by Vincenzo Quercioli. Here, he reported the photographic documentation of an autopsy specimen regarding a fracture of the atlas. It is evident that symmetrical fractures in the anterior and posterior arches defined a "quadripartite" fracture.

toaxial ligaments, which appeared to be distracted, but not torn, and thus able to maintain a stable odontoid process in the axis.

Quercioli speculated that this situation was related to the partial preservation of the ligaments, especially the transverse ligament, despite the contraction of the neck muscles. He continued with his hypothesis by stating that a tearing of the ligaments, particularly the transverse ligament, would have allowed the dens to come in contact with the spinal cord, and this would have damaged the spinal cord, and the patient would have died.

Based on these considerations, Quercioli stated that, "in altre parole la frattura comminuta dell'atlante può essere non mortale e guaribile" ("in other words, the comminuted fracture of the atlas may be nonfatal and curable"). Furthermore, in terms of biomechanics, the bilateral lesion of the hypoglossal nerve was explained by the lateral displacement, although modest, of the lateral masses of C-1.

However, according to Quercioli, the prognosis of these fractures is tied to the immediate treatment of the 
patient. In his case, he inserted a nasogastric tube to prevent pulmonary aspiration and he supported the neck with a Minerva cast. The delay between the accident and the application of these principles was cited to explain the deterioration and death of the patient. With this in mind, the author drew attention to the fact that the treatment of " ... a lesion previously thought to be immediately fatal, such as comminuted suboccipital fracture, may serve to prevent, in similar cases, the abandonment of therapeutic aids hitherto deemed unnecessary."

\section{The Career of Vincenzo Quercioli}

Professor Vincenzo Quercioli (Fig. 3) was born in Italy, outside the walls of Siena, on April 10, 1876. He graduated in Medicine and Surgery from the University of Siena in 1902. From 1903, he held prestigious positions at the Institute of General Clinical Surgery, at that time directed by Professor Domenico Biondi. He was second assistant surgeon from February 1, 1903, to October 31, 1906; first assistant surgeon from November 1, 1906, to October 31, 1907; and second surgeon from November 1, 1907, until October 31, 1908. During that period, the fields of interest to which he devoted himself regarded mainly the surgical treatment of suppurative otitis media; the surgical indications in spinal trauma, with particular regard to the use of decompressive laminectomy; and studies related to Jacksonian epilepsy. At that time, he successfully performed more than 2000 surgical procedures, including some craniotomies.

From 1904 to 1908, he played a key role as a member of the "Accademia dei Fisiocritici" of Siena, a famous Italian scientific institution founded in 1691, which continues its operations today. The paper on the fracture of the atlas dates from that period.

His university career was interrupted in 1909, when he moved to Montalcino in the province of Siena, where he held the position of Director of the Royal Hospital "Santa Maria della Croce." In 1912, he took part in the Italian-Turkish war as an army doctor, and he was sent to Salonicco, which is currently Tessalonica, a Greek city. Upon returning from the war, he resumed his position as Director of the Hospital of Montalcino, which he held until his retirement for health reasons in 1935 . He died in Montalcino on June 30, 1939.

\section{Discussion}

Fractures of the atlas, either isolated or associated with the skull base or other cervical vertebrae fractures, do not currently have a uniquely recognized classification system in the literature. However, in the literature, descriptions of those fractures are based on the 1920s classifications proposed by Sir Geoffrey Jefferson. ${ }^{6}$ In his classic work, Jefferson presented a description of 2 personally observed cases, 2 museum specimens, and a review of 42 additional cases from the literature that involved all types of atlas fractures. The personally observed cases consisted of a blunt fracture in 2 places in the posterior arch and a fracture of the lateral mass, due to a gunshot injury. Of the 2 museum specimens, 1 consisted of a fracture in 2 places in the posterior arch of the atlas vertebra, with a fracture

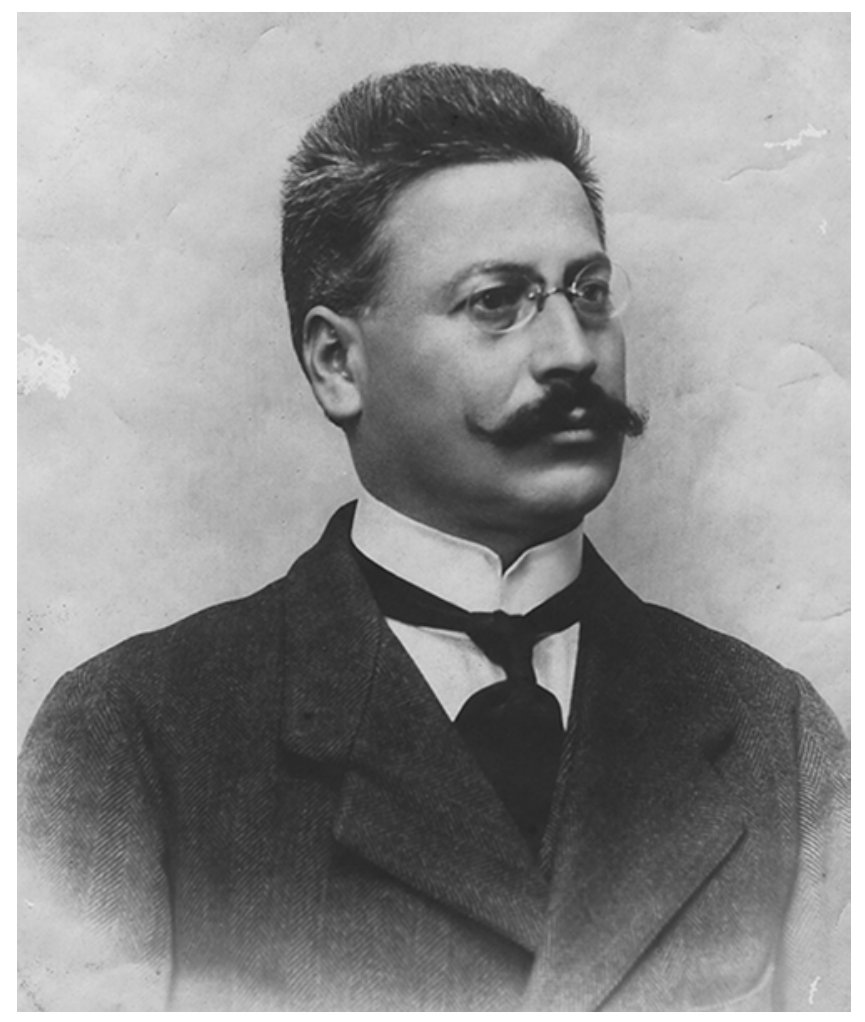

FIG. 3. Original photograph portraying Professor Vincenzo Quercioli at the time of his residency (1903-1908) at the Institute of "Clinica Generale Operativa" at the University of Siena, at that time directed by Professor Domenico Biondi. Quercioli served as assistant surgeon under Professor Biondi during his university residency.

in the right transverse process; the other was a fracture in the anterior and posterior arches of the atlas vertebra with a fracture of the odontoid process. Based on this series, Sir Geoffrey Jefferson distinguished between fractures of the atlas in isolation and those associated with the rupture of another vertebra, and he identified 5 anatomical types of atlas fractures. Of these 5 types, 3 referred to the arches, including the posterior, anterior, or both arches; and 2 were related to fractures of the lateral mass, including either an isolated fracture or a fracture associated with another fracture of the posterior arch. 6,7

In his work, Jefferson also formed a hypothesis on the biomechanics of the atlas ring fracture. Excluding injuries from direct violence with firearms, he assumed 3 possible mechanisms that could fracture the vertebra, as follows: ${ }^{6}$

(1) Fractures of one or both arches by transmitted force causing a lateral spread of the bone (the odontoid may perhaps be broken in addition, by pressure from the distorted anterior arch). (2) Fracture of the posterior arch by crushing it between the occiput and the neural arch of the axis, with the head in full extension. (3) Fracture of the anterior arch by pressure against the odontoid, with the head in full extension.

The analysis of the mechanisms of fracture ended with a description of the distribution of the forces. The force is transmitted from the vertex, through the occipital condyles, to the vertebral column. This force is collected at the base of the skull, and transmitted to the atlas from the occipital condyles, which then compresses the atlas 
between the base of the skull and the axis; then, depending on the particular inclination of the articular surfaces of its lateral masses, there is a displacement that causes the arches to fracture. In summary, Jefferson suggested 2 schematic representations of the atlas, 1 in an axial view and 1 in a coronal view, which showed the relationship between the forces and the fracture lines on the vertebra that would cause the atlas to fracture into 4 symmetrical parts. These schematics represented a symmetrical, quadripartite fracture of the atlas.

A careful review of Sir Geoffrey Jefferson's work led us to find that the only quadripartite fracture of the atlas, like the one schematically drawn by the author, was represented by the case described by Professor Vincenzo Quercioli. Jefferson, quoting Quercioli in his manuscript, reported: "The atlas is broken into four pieces by symmetrical fractures in both arches." These findings led us to believe that, during the drafting of his manuscript, Jefferson took into account the anatomical descriptions and theories of Quercioli. We believe that Jefferson used Quercioli's concepts to formulate a classification system based on mechanisms that led to all the fractures of the atlas.

Quercioli was the first to describe a symmetrical quadripartite fracture of the atlas. Moreover, in his paper he provided a careful description of the patient's neurological symptoms and he offered anatomical findings from an autopsy performed after the patient's death. Through these clinical and anatomical observations, Quercioli succeeded in providing an effective biomechanics theory of the traumatic event, based on the principles of physics; he concluded with prognostic and therapeutic solutions for this type of fracture, which remain valid. These achievements take on more importance when we consider that, at the time his work was written, knowledge of a fracture of the atlas was poor, and the biomechanics were unknown.

In the anatomical description Quercioli provided, the atlantoaxial ligaments were intact, particularly the transverse ligament. He also stated that the odontoid was stable, and therefore the spinal cord had not been damaged, and the patient did not present with neurological disorders related to CNS lesions. These concepts related to odontoid mobility, which were clearly expressed by Quercioli and unknown at the time he wrote the paper, anticipating the conclusions reached in modern scientific literature, ${ }^{1-3,11,12}$ that is, the integrity of the transverse ligament is important for deciding whether these lesions should be treated conservatively or surgically.

In his paper, Quercioli described the cause of a quadripartite fracture of the atlas: the arches were points of minor resistance and, in particular, he described the mechanism for transmitting a violent force applied to the C-1 articular masses. Due to the position and shape of the C-1 vertebra, according to Quercioli, it behaved according to the physical laws that governed the "wedge." The particular inclination of the articular surfaces of the atlas vertebra, and the central and axial position of the resultant forces provoked by the trauma with respect to the $\mathrm{C}-1$ ring, caused the displacement of the articular masses, the distention of the arches of the atlas, and their consequent fracture at 4 symmetrical points of minor resistance. Looking at Jefferson's designs,${ }^{6}$ in which he traced the lines of force that caused the 4-point fractures in the ring of the atlas, we recognize the exact description of the mechanisms proposed by Quercioli. Therefore, we believe that Jefferson used these concepts as the basis for his own theories.

Finally, the prognostic and therapeutic intuitions of Quercioli should be highlighted. He believed that atlas fractures were not fatal in cases in which they could be appropriately treated by immobilization with a Minerva cast and placement of a nasogastric tube to avoid possible complications.

Despite the time that has passed since Quercioli's work was published, his perceptions have not gone unnoticed. In past years, he was cited in the Italian literature in a few works, like those of Fumagalli ${ }^{3}$ and Pieri. ${ }^{9}$ Also, in recent literature, he was mentioned by Beckner et al. ${ }^{1}$ in a 1998 study titled "A biomechanical study of Jefferson fractures." There, Beckner and colleagues placed Quercioli among scientists who had written clinical reports and performed laboratory tests on tripartite or quadripartite C-1 fractures.

\section{Conclusions}

Classifications of atlas fractures are currently controversial. Sir Geoffrey Jefferson, based on a literature review and on 4 personal observations, was the first to provide a systematic classification. He divided the fractures into 5 anatomopathological categories. The modern international literature correctly uses this classification as a reference, and his name is identified as a pioneer of the atlas fracture. We believe we have identified another pioneer in the field of atlas fractures in Professor Vincenzo Quercioli. Quercioli deserves recognition for having described the first quadripartite fracture of the $\mathrm{C}-1$ vertebra. Moreover, he described the mechanics of this traumatic fracture, based on a careful evaluation of the clinical and pathological events that he observed. On the basis of those findings, Quercioli proposed a biodynamic model of this type of fracture that was absolutely original for the era. The model he proposed remains currently valid and recognized.

\section{Acknowledgments}

We thank Prof. Sara Ferri, actual President of "Accademia dei Fiosiocritici" of Siena, for support in providing academic details regarding Professor Quercioli's activity during his partnership with this ancient and prestigious institution. Moreover, we thank Mr. Luigi Pozzi, the publisher of the journal Il Policlinico, for his cooperation in acquiring the original article of Professor Quercioli. Finally, we thank Dr. Antonio Quercioli, Professor Vincenzo Quercioli's grandnephew, for support in providing Professor Quercioli's original photograph and life details.

\section{References}

1. Beckner MA, Heggeness MH, Doherty BJ: A biomechanical study of Jefferson fractures. Spine (Phila Pa 1976) 23:18321836,1998

2. Boos N, Aebi M: Spinal Disorders: Fundamentals of Diagnosis and Treatment. New York: Springer, 2008, p 1166

3. Fumagalli CR: Le fratture del rachide. Arch Ortop 46:7383,1930 
4. Hays MB, Alker GJ Jr: Fractures of the atlas vertebra. The two-part burst fracture of Jefferson. Spine (Phila Pa 1976) 13:601-603, 1988

5. Jeanneret B: Classification of injuries of the upper cervical spine, in Aebi M, Arlet V, Webb JK, (eds): AO Spine Manual. Clinical Applications, Vol 2. New York: Thieme, 2007, pp 9-19

6. Jefferson G: Fracture of the atlas vertebra: report of four cases, and a review of those previously recorded. Br J Surg 7:407-422, 1920

7. Jefferson G: Remarks on fractures of the first cervical vertebra. Br Med J 2:153-157, 1927

8. Lee TT, Green BA, Petrin DR: Treatment of stable burst fracture of the atlas (Jefferson fracture) with rigid cervical collar. Spine (Phila Pa 1976) 23:1963-1967, 1998

9. Pieri G: Le lesioni traumatiche della colonna vertebrale. Seconda parte. Archivio di Ortopedia 33:363-545, 1917

10. Quercioli V: Considerazioni cliniche su di un caso di frattura isolata comminuta simmetrica dello atlante senza lesioni midollari in seguito a caduta sul capo. Il Policlinico XVC:241-255, 1908
11. Ryken TC, Aarabi B, Dhall SS, Gelb DE, Hurlbert RJ, Rozzelle CJ, et al: Management of isolated fractures of the atlas in adults. Neurosurgery 72 (Suppl 2):127-131, 2013

12. Spence KF Jr, Decker S, Sell KW: Bursting atlantal fracture associated with rupture of the transverse ligament. J Bone Joint Surg Am 52:543-549, 1970

\section{Author Contributions}

Conception and design: Domenicucci. Acquisition of data: Mancarella, D'Elia. Analysis and interpretation of data: Mancarella, Dugoni. Drafting the article: Dugoni. Critically revising the article: Domenicucci. Reviewed submitted version of manuscript: Mancarella. Study supervision: Missori.

\section{Correspondence}

Cristina Mancarella, "Sapienza" University of Rome, viale del Policlinico 155, 00161 Rome, Italy. email: cristinamancarella@ gmail.com. 